\title{
Factors associated with colonoscopy performed in nonhospital settings
}

\author{
Othman Alharbi MBBS FRCPC ${ }^{1}$, Linda Rabeneck MD MPH FRCPC ${ }^{2}$, Lawrence F Paszat MD MSc FRCPC ${ }^{3}$, \\ Duminda N Wijeysundera MD FRCPC ${ }^{4}$, Rinku Sutradhar $\mathrm{PhD}^{5}$, Lingsong Yun $\mathrm{MSc}^{5}$, \\ Christopher M Vinden MD FRCSC ${ }^{6}$, Jill Tinmouth MD PhD FRCPC ${ }^{2}$
}

\begin{abstract}
O Alharbi, L Rabeneck, LF Paszat, et al. Factors associated with colonoscopy performed in nonhospital settings. Can J Gastroenterol 2010;24(7):419-424.
\end{abstract}

BACKGROUND: Colonoscopy is being increasingly performed in facilities outside of hospitals. Regulation of these facilities is variable, and concerns regarding the quality of procedures in nonhospital $(\mathrm{NH})$ settings have been raised. Further study is needed to better understand endoscopic practice in these facilities.

OBJECTIVES: To describe NH-based colonoscopy practice in Ontario from 1993 to 2005, and to identify patient (age, sex, income quintile and comorbidity) and physician (specialty and colonoscopy volume) factors associated with this practice.

METHODS: The present study was a population-based, cross-sectional analysis using health administrative data from Ontario adults who underwent at least one outpatient colonoscopy between 1993 and 2005. A total of $1,240,781$ patients underwent $1,917,714$ colonoscopies. The main outcome measure was the receipt of colonoscopy in an NH facility.

RESULTS: An increase in NH-based colonoscopy from $10.0 \%$ in 1993 to $15.1 \%$ in $2005(\mathrm{P}<0.0001)$ was found. In the multivariate model, younger, healthier men living in higher income areas were significantly more likely to undergo NH-based colonoscopy. Surgeons and other practitioners (eg, nongastroenterologists and noninternists) were significantly more likely to practice in $\mathrm{NH}$ settings. Physicians in the highest colonoscopy volume quintile were 25 times more likely to practice in $\mathrm{NH}$ settings than those in the lowest volume quintile $(\mathrm{P}<0.0001)$

CONCLUSION: Rates of NH-based colonoscopy are rising in Ontario. High-volume endoscopists and surgeons are most likely to practice in $\mathrm{NH}$ settings. Given its increasing use, further study of the practice and the regulation of $\mathrm{NH}$ colonoscopy is warranted.

\section{Les facteurs associés à la coloscopie effectuée en milieu non hospitalier}

\begin{abstract}
HISTORIQUE : Les coloscopies sont de plus en plus effectuées en milieu non hospitalier $(\mathrm{MNH})$. La réglementation liée à ces milieux est variable, et des inquiétudes ont été soulevées quant à la qualité des interventions qui y sont effectuées. Des études s'imposent pour mieux comprendre les pratiques endoscopiques qui y sont exécutées.

OBJECTIFS : Décrire les pratiques de coloscopie en MNH en Ontario de 1993 à 2005 et déterminer les facteurs liés aux patients (âge, sexe, quintile de revenu et comorbidité) et aux médecins (spécialité et volume de coloscopie) qui s'y associent.

MÉTHODOLOGIE : La présente étude était une analyse transversale en population faisant appel à des données administratives de santé obtenues auprès d'adultes ontariens qui avaient subi au moins une coloscopie en consultations externes entre 1993 et 2005. Au total, 1240781 patients ont subi 1917714 coloscopies. La principale mesure d'issue était la tenue d'une coloscopie en MNH.

RÉSULTATS : Le taux de coloscopies en MNH est passé de 10,0 \% en 1993 à $15,1 \%$ en $2005(\mathrm{P}<0,0001)$. Selon le modèle multivarié, des hommes plus jeunes et en meilleure santé provenant de régions à plus fort revenu étaient beaucoup plus susceptibles de subir une coloscopie en MNH. Les chirurgiens et les autres praticiens (p. ex., non-gastroentérologues et non-internistes) étaient beaucoup plus susceptibles d'exercer en MNH. Les médecins faisant partie du quintile de volume de coloscopie le plus élevé étaient 25 fois plus susceptibles d'exercer en $\mathrm{MNH}$ que ceux qui faisaient partie du quintile de volume le plus faible $(\mathrm{P}<0,0001)$.

CONCLUSION : Le taux de coloscopies en MNH augmente en Ontario. Les endoscopistes et les chirurgiens qui en font de forts volumes sont plus susceptibles d'exercer en MNH. Étant donné l'utilisation croissante des coloscopies, des études plus approfondies de la pratique et de la réglementation des coloscopies en $\mathrm{MNH}$ sont justifiées.
\end{abstract}

Key Words: Colonoscopy; Hospital; Nonhospital settings; Ontario; Population-based studies

Colonoscopy is fundamental to the diagnosis and treatment of many digestive diseases because it permits direct visual inspection of colonic mucosa, and enables tissue sampling and therapeutic manoeuvres such as polypectomy. In Canada, colonoscopy rates have doubled since the 1990s (1,2). Colonoscopy is used increasingly as a screening tool for colorectal cancer (CRC) (3). Given the new province-wide CRC screening programs launched in Ontario (4), Manitoba (5) and
Alberta (6), as well as similar programs being considered in Quebec and British Columbia (7), Canadian colonoscopy use is projected to increase even further over the next several years.

In Canada, the proportion of colonoscopies that are performed in nonhospital (NH) settings is unknown. The considerable nonphysician costs (eg, rent, nursing salaries, equipment and medications) that are associated with hospital-based

${ }^{1}$ Department of Medicine, Division of Gastroenterology; ${ }^{2}$ Department of Medicine, Division of Gastroenterology, Sunnybrook Health Sciences Centre, Institute for Clinical Evaluative Sciences; ${ }^{3}$ Department of Radiation Oncology, Sunnybrook Health Sciences Centre; Institute for Clinical Evaluative Sciences; ${ }^{4}$ Department of Anesthesia, University Health Network; Institute for Clinical Evaluative Sciences; University of

Toronto; ${ }^{5}$ Institute for Clinical Evaluative Sciences, Toronto; ${ }^{6}$ Department of Surgery, University of Western Ontario, London, Ontario

Correspondence: Dr Jill Tinmouth, Department of Medicine, Division of Gastroenterology, Sunnybrook Health Sciences Centre, University of

Toronto, Institute for Clinical Evaluative Sciences, 2075 Bayview Avenue, Room HG40, Toronto, Ontario M4N 3M5.

Telephone 416-480-5910, fax 416-480-4845, e-mail jill.tinmouth@sunnybrook.ca

Received for publication March 24, 2009. Accepted January 11, 2010 


\begin{tabular}{|c|c|c|}
\hline OHIP procedure code & Procedure & $\begin{array}{c}\text { Billable } \\
\text { fee }^{*}, \$\end{array}$ \\
\hline Z555 & $\begin{array}{l}\text { Insertion of colonoscope to } \\
\text { descending colon }\end{array}$ & 57.70 \\
\hline Z555 + E740 & $\begin{array}{l}\text { Insertion of colonoscope to } \\
\text { splenic flexure }\end{array}$ & 115.40 \\
\hline Z555 + E740 + E741 & $\begin{array}{l}\text { Insertion of colonoscope to } \\
\text { hepatic flexure }\end{array}$ & 150.30 \\
\hline $\begin{array}{l}\text { Z555 + E740 + E741+ } \\
\text { E747 }\end{array}$ & $\begin{array}{l}\text { Insertion of colonoscope to } \\
\text { cecum }\end{array}$ & 185.20 \\
\hline $\begin{array}{l}\text { Z555 + E740 + E741+ } \\
\text { E747+ E705 }\end{array}$ & $\begin{array}{l}\text { Insertion of colonoscope to } \\
\text { terminal ileum }\end{array}$ & 219.10 \\
\hline E749 & Procedure performed outside hospital & 22.35 \\
\hline
\end{tabular}

*Data from the OHIP Schedule of Benefits and Fees, October 1, 2009

colonoscopy are contained within hospitals' fixed global budgets. Because of budget constraints, the number of colonoscopies that are performed in hospitals is limited. In the context of the rising demand for this procedure in Canada, colonoscopies are increasingly being performed in offices and clinics outside of hospitals.

In Ontario and in other Canadian provinces such as Alberta, British Columbia, Manitoba, Nova Scotia and Quebec, colonoscopies may be performed in NH facilities. Only two provinces British Columbia and Alberta - regulate and monitor private medical facilities (8). In most Canadian provinces, NH-based endoscopy facilities are unregulated and few funds (only approximately $\$ 20$ per procedure), if any, are provided by the government to cover the considerable endoscopy-related overhead costs outlined above. Alberta is a particularly notable exception in the arena of NH-based endoscopy. Recently, The Forzani \& McPhail Colon Cancer Screening Centre (Calgary, Alberta), an accredited outpatient endoscopy facility funded by the Calgary Health Region, has opened $(9,10)$.

In population-based studies conducted in Ontario, we previously reported (11) higher rates of incomplete colonoscopy and of missed CRC (12), as well as lower rates of achieving complete colonic evaluation following incomplete colonoscopy (13) in NH settings. The reasons for these findings are not well understood. Variations in billing practices across physicians or types of facilities may play a role; however, patient, physician or other factors (eg, differing sedation practices) that are particular to $\mathrm{NH}$ endoscopy facilities may also be important contributors. To better understand endoscopic practice in these facilities, we conducted a population-based analysis of NH-based outpatient colonoscopy. The objectives of the present study were to describe the pattern of $\mathrm{NH}$-based colonoscopy practice in Ontario from 1993 to 2005, and to identify associated patient and physician factors.

\section{METHODS}

The research ethics board of the Sunnybrook Health Sciences Centre (Toronto, Ontario) approved the study.

\section{Data sources}

The present study was conducted at the Institute for Clinical Evaluative Sciences (ICES) (Toronto, Ontario), which houses the health records of all 12.4 million residents of Ontario. These records are held in administrative databases and may be linked by an encrypted version of each resident's health plan number.

For the current study, the databases from the following programs were used: Canadian Institute for Health Information (CIHI) Discharge Abstract Database (CIHI-DAD), the CIHI Same Day Surgery (CIHI-SDS) database, the Ontario Health Insurance Plan (OHIP), the Registered Persons Database and the ICES Physician Database (IPDB). The CIHI-DAD contains clinical, demographic and administrative data for all hospital admissions and for outpatient procedures (CIHI-SDS) including endoscopy since April 1, 1988. The OHIP database holds physician billing claims for both procedures and consultation visits since July 1, 1991. The Registered Persons Database has maintained age, sex, postal code information and vital statistics for all Ontario residents with a valid OHIP number in Ontario since 1991. The IPDB, which is derived from the Corporate Provider Database, the Ontario Physician Human Resource Data Centre database and OHIP, provided information regarding physician specialty.

\section{Study cohort}

Using the OHIP database, all Ontario adults older than 19 years of age who underwent at least one outpatient colonoscopy between April 1, 1993 and March 31, 2006, were identified. Using OHIP procedure fee codes, colonoscopy was defined as the insertion of the colonoscope to or beyond the splenic flexure (Table 1). Because there is a separate OHIP fee code for flexible sigmoidoscopy (Z580), this definition of colonoscopy likely captured all complete and incomplete colonoscopies.

\section{Definition of $\mathrm{NH}$ - and hospital-based colonoscopy}

Colonoscopy setting was categorized as hospital, $\mathrm{NH}$ or not classifiable. The setting was identified as a hospital (outpatient) if there was a CIHI-SDS record for the colonoscopy without an overlapping record in the CIHI-DAD, indicating hospital admission. The setting was defined as NH if OHIP code E749 (additional fee for colonoscopies performed outside hospitals) was billed in the absence of a concurrent CIHI-DAD or CIHISDS record for the colonoscopy. OHIP claims for colonoscopy without records in CIHI-DAD, CIHI-SDS and without an E749 claim were considered to be not classifiable.

It was not possible to identify individual $\mathrm{NH}$ institutions using the administrative data. Unlike other health care institutions, such as hospitals or nursing homes, that can be identified in the administrative data by an institution number, individual $\mathrm{NH}$ facilities are not registered or regulated and, consequently, do not have institution numbers assigned to them.

\section{Factors examined}

Patient factors: Data regarding patient age, sex, comorbidity, neighbourhood income quintile and patient health region known as the Local Health Integration Network (LHIN) were collected on the date of colonoscopy.

Comorbidity was measured using the Johns Hopkins casemix system (14). This system was developed to measure patient morbidity and its impact on inpatient and outpatient health resource use, and has been validated in the United States $(15,16)$ and Canada $(17,18)$. The Johns Hopkins case-mix system assigns patients to categories based on their inpatient and outpatient health care records over a specified period of 
time. For the present study, the Ontario inpatient (CIHI) and outpatient (OHIP) diagnosis codes from the year before colonoscopy were used to estimate case-mix using the Johns Hopkins algorithm. Specifically, comorbidity was adjusted for by using aggregated diagnosis groups (ADGs), which are clinically meaningful groupings of diagnoses. Diagnoses within a given ADG are similar in terms of disease severity and anticipated duration. Comorbidity was categorized according to the number of ADGs (zero, one to three, four to five, six to seven, and eight or more). ADGs were selected as a comorbidity measure because they were more suitable for our outpatient cohort than other commonly used measures such as the Deyo adaptation of the Charlson score (19), which relies on inpatient diagnosis codes only. Compared with the Deyo score, missing comorbidity data in patients without previous hospital admissions was minimized using the Johns Hopkins system (data not shown), likely because of its use of outpatient diagnosis codes.

The median annual neighbourhood household income according to enumeration area (obtained from Statistics Canada) was linked to patients' postal codes. This strategy has been used by others $(20,21)$ to impute socioeconomic status.

LHINs are not-for-profit organizations operating in Ontario's 14 health regions that, as of April 2007, are responsible for planning, integrating and funding local health services (22). An ICES algorithm that maps each patient's Ontario Ministry of Health and Long-Term Care residence code was used to determine patient LHIN.

\section{Physician factors}

Physician specialty was categorized as gastroenterology, surgery, internal medicine and other practitioners. The other practitioner category comprised all other specialties including family physicians and general practitioners. For each year of the study, physicians were assigned to colonoscopy volume quintiles based on the mean annual number of colonoscopies performed in the preceding five years. Colonoscopies performed in both hospitals and $\mathrm{NH}$ clinics were included in the volume estimates.

\section{Data analysis}

The number of colonoscopies performed in each type of colonoscopy setting per fiscal year during the study period was determined. Patient (age, sex, comorbidity and income quintile), and physician (specialty and volume) characteristics are reported according to colonoscopy setting (hospital versus $\mathrm{NH}$ ) for the entire study period. For the 2005 fiscal year, the age- and sex-adjusted rate of colonoscopy in each setting, standardized to the 2001 Canadian population, was calculated according to LHIN. Where appropriate, the $\chi^{2}$ test was used to assess trends and to compare the proportions of nominal or categorical variables.

Multivariable logistic regression models were constructed to evaluate the relationship between colonoscopy setting and patient and physician factors. The model parameters were estimated using Generalized Estimating Equation methods with exchangeable correlation structures to account for clustering of patients within physicians. Because Generalized Estimating Equation methods cannot simultaneously handle clustering at more than one level, clustering of multiple colonoscopies within patients was avoided by restricting the sample to the

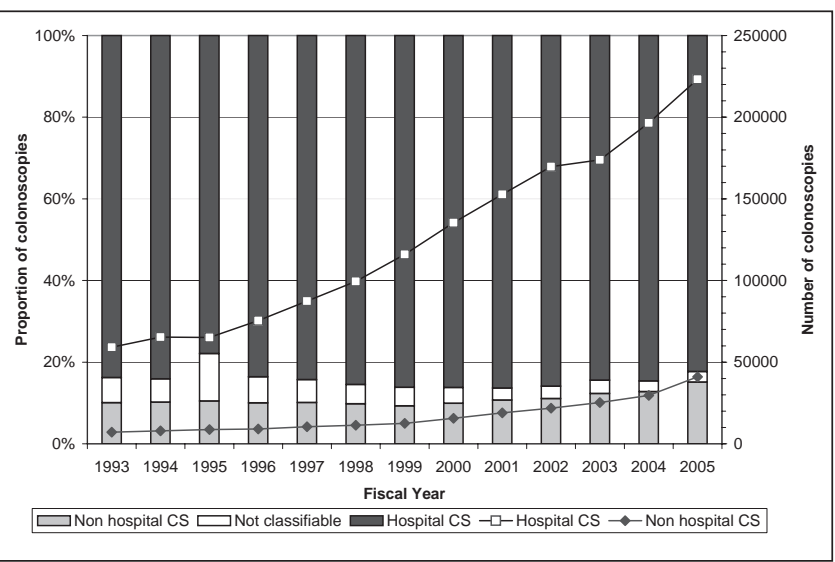

Figure 1) Annual number and proportion of colonoscopies performed in Ontario according to setting (hospital, nonhospital and not classifiable) from 1993 to 2005. CS Colonoscopies

first colonoscopy performed on all patients who had at least one of these procedures in 2005. Hierarchical regression techniques were also implemented for modelling this relationship using the generalized linear mixed methods procedure (SASPROC GLIMMIX) and MLwiN software (Centre for Multilevel Modeling, United Kingdom); however, these techniques were not successful because convergence of the estimates of the model parameters was not achieved. It was theorized that this failure in convergence was due to the distribution of colonoscopy settings across physicians. Specifically, $87.5 \%$ of the physicians practiced exclusively in either hospital or $\mathrm{NH}$ settings, which itself provided a strong indication that a large proportion of the unexplained variation in colonoscopy setting may have been attributable to physician characteristics.

Except for the hierarchical modelling mentioned above, all analyses were performed using SAS version 9 (SAS Institute, USA).

\section{RESULTS}

During the study period, 1,240,781 individuals underwent a total of $1,917,714$ outpatient colonoscopies. A total of $1,619,366$ colonoscopies $(84.4 \%)$ were performed in hospitals, while 219,513 colonoscopies (11.4\%) were performed in $\mathrm{NH}$ settings; 78,835 procedures $(4.1 \%)$ were not classifiable. During this time period, the total number of outpatient colonoscopies rose from 70,542 in 1993, to 271,258 in 2005 $(\mathrm{P}<0.0001)$, with the proportion of colonoscopies performed in $\mathrm{NH}$ settings accounting for an increasingly larger share from $10.0 \%$ in 1993, to $15.1 \%$ in $2005(\mathrm{P}<0.0001)$ (Figure 1). Patient and physician characteristics of the entire study cohort are summarized in Tables 2 and 3, respectively.

In the multivariate analysis (limited to the 251,985 patients who underwent one or more colonoscopies in 2005), younger, healthier men living in higher income neighborhoods were more likely to receive colonoscopy in $\mathrm{NH}$ settings. Higher volume physicians, surgeons and other practitioners were more likely to practice in NH settings (Table 4). For patients who had their procedure performed by a physician in the highest volume quintile, the OR of having an $\mathrm{NH}$ procedure was 25 times greater than for those who had their procedure completed by a physician in the lowest volume quintile (95\% CI 10 to $50 ; \mathrm{P}<0.0001$ ). Moreover, for patients who had their procedure performed by 
TABLE 2

Patient characteristics for hospital- and nonhospital-based outpatient colonoscopy in Ontario between 1993 and 2005

\begin{tabular}{|c|c|c|c|c|}
\hline & \multicolumn{2}{|c|}{ Colonoscopy } & \multirow[b]{2}{*}{$\begin{array}{c}\text { Total } \\
(n=1,838,879)\end{array}$} & \multirow[b]{2}{*}{$\mathrm{P}^{*}$} \\
\hline & $\begin{array}{c}\text { Nonhospital } \\
\text { based } \\
(n=219,513)\end{array}$ & $\begin{array}{c}\text { Hospital } \\
\text { based } \\
(n=1,619,366)\end{array}$ & & \\
\hline Age, years & & & & $<0.0001$ \\
\hline $19-50$ & $65,087(30)$ & $499,260(31)$ & $564,347(31)$ & \\
\hline $51-70$ & $124,210(57)$ & $783,978(48)$ & 908,188 (49) & \\
\hline$>70$ & 30,216 (14) & $336,128(21)$ & $366,344(20)$ & \\
\hline Sex & & & & $<0.0001$ \\
\hline Female & $101,339(46)$ & $860,597(53)$ & $961,936(52)$ & \\
\hline Male & $118,174(54)$ & $758,769(47)$ & $876,943(48)$ & \\
\hline \multicolumn{2}{|c|}{ Neighbourhood income quintile } & & & $<0.0001$ \\
\hline Low & $26,057(12)$ & $252,223(16)$ & $278,280(15)$ & \\
\hline 2 & $31,314(14)$ & $300,503(19)$ & $331,817(18)$ & \\
\hline 3 & $35,958(16)$ & $318,409(20)$ & $354,367(19)$ & \\
\hline 4 & $43,592(20)$ & $334,304(21)$ & $377,896(21)$ & \\
\hline High & $78,447(36)$ & $379,000(23)$ & $457,447(25)$ & \\
\hline Unknown & $4145(2)$ & $34,927(2)$ & $39,072(2)$ & \\
\hline Comorbidity $^{\dagger}$ & & & & $<0.0001$ \\
\hline None & $2347(1)$ & $8640(1)$ & $10,987(1)$ & \\
\hline $1-3$ & $61,130(28)$ & $350,758(22)$ & $411,888(22)$ & \\
\hline $4-5$ & $63,378(29)$ & $448,787(28)$ & $512,165(28)$ & \\
\hline $6-7$ & $48,171(22)$ & $383,552(24)$ & 431,723 (23) & \\
\hline$\geq 8$ & $44,487(20)$ & $427,629(26)$ & $472,116(26)$ & \\
\hline
\end{tabular}

Data presented as $n$ (\%) unless indicated otherwise. ${ }^{*}$ Calculated for overall comparison among groups; ${ }^{\dagger}$ Comorbidity scored using number of aggregated diagnosis groups

TABLE 3

Physician characteristics for hospital- and nonhospitalbased outpatient colonoscopy in Ontario from 1993 to 2005

\begin{tabular}{|c|c|c|c|c|}
\hline & \multicolumn{2}{|c|}{ Colonoscopy } & \multirow[b]{2}{*}{$\begin{array}{c}\text { Total } \\
(n=1,838,879)\end{array}$} & \multirow[b]{2}{*}{$\mathbf{P}^{*}$} \\
\hline & $\begin{array}{c}\text { Nonhospital } \\
\text { based } \\
(n=219,513)\end{array}$ & $\begin{array}{c}\text { Hospital } \\
\text { based } \\
(n=1,619,366)\end{array}$ & & \\
\hline \multicolumn{4}{|l|}{ Specialty } & \multirow[t]{5}{*}{$<0.0001$} \\
\hline Gastroenterology & $63,525(29)$ & $670,179(41)$ & $733,704(40)$ & \\
\hline General surgery & $122,248(56)$ & $708,219(44)$ & $830,467(45)$ & \\
\hline Internal medicine & $13,657(6)$ & $178,501(11)$ & $192,158(10)$ & \\
\hline Other practitioners & $20,083(9)$ & $62,467(4)$ & $82,550(5)$ & \\
\hline \multicolumn{3}{|c|}{ Physician volume quintile } & & \multirow[t]{6}{*}{$<0.0001$} \\
\hline Low & $13,469(6)$ & $350,741(22)$ & $364,210(20)$ & \\
\hline 2 & $11,527(5)$ & $356,459(22)$ & $367,986(20)$ & \\
\hline 3 & $22,444(10)$ & $346,566(21)$ & $369,010(20)$ & \\
\hline 4 & $39,893(18)$ & $329,067(20)$ & $368,960(20)$ & \\
\hline High & $132,180(60)$ & $236,533(15)$ & $368,713(20)$ & \\
\hline
\end{tabular}

Data presented as $n$ (\%) unless indicated otherwise. ${ }^{*}$ Calculated for overall comparison among groups

a surgeon, the $\mathrm{OR}$ of having an $\mathrm{NH}$ procedure was 3.8 times greater than for those who had their procedure completed by a gastroenterologist $(95 \%$ CI 1.7 to $8.4 ; \mathrm{P}=0.0009$ ) while the $\mathrm{OR}$ was 6.1 times greater than those who had it performed by an other practitioner (95\% CI 2.0 to $18.8 ; \mathrm{P}<0.002$ ).
TABLE 4

Results from the multivariate logistic regression model using generalized estimating equations. Patient and physician characteristics associated with nonhospitalbased colonoscopy in Ontario in $2005(n=251,985)$

\begin{tabular}{|c|c|c|}
\hline Patient characteristics & OR $(95 \% \mathrm{Cl})$ & $\mathbf{P}$ \\
\hline \multicolumn{3}{|l|}{ Age group, years } \\
\hline $19-50$ & $1.4(1.2-1.6)$ & $<0.0001$ \\
\hline $51-70$ & $1.5(1.4-1.7)$ & $<0.0001$ \\
\hline$>70$ & 1 & N/A \\
\hline \multicolumn{3}{|l|}{ Sex } \\
\hline Male & $1.1(1.0-1.2)$ & 0.01 \\
\hline Female & 1 & N/A \\
\hline \multicolumn{3}{|c|}{ Neighbourhood income quintile } \\
\hline Low & $0.6(0.5-0.8)$ & $<0.0001$ \\
\hline 2 & $0.6(0.5-0.7)$ & $<0.0001$ \\
\hline 3 & $0.6(0.5-0.7)$ & $<0.0001$ \\
\hline 4 & $0.7(0.6-0.8)$ & $<0.0001$ \\
\hline High & 1 & N/A \\
\hline \multicolumn{3}{|l|}{ Comorbidity* } \\
\hline None & $2.0(0.9-4.1)$ & NS \\
\hline $1-3$ & $1.4(1.2-1.7)$ & $<0.0001$ \\
\hline $4-5$ & $1.2(1.1-1.3)$ & $<0.0001$ \\
\hline $6-7$ & $1.2(1.1-1.2)$ & $<0.0001$ \\
\hline$\geq 8$ & 1 & N/A \\
\hline \multicolumn{3}{|c|}{ Physician characteristics } \\
\hline \multicolumn{3}{|l|}{ Specialty } \\
\hline General surgery & $3.8(1.7-8.4)$ & 0.0009 \\
\hline Internal medicine & $1.7(0.5-5.7)$ & NS \\
\hline Other practitioners & $6.1(2.0-18.8)$ & 0.002 \\
\hline Gastroenterology & 1 & N/A \\
\hline \multicolumn{3}{|c|}{ Endoscopist volume quintile } \\
\hline Low & $0.04(0.02-0.1)$ & $<0.0001$ \\
\hline 2 & $0.03(0.01-0.1)$ & $<0.0001$ \\
\hline 3 & $0.05(0.02-0.1)$ & $<0.0001$ \\
\hline 4 & $0.3(0.1-0.6)$ & 0.0025 \\
\hline High & 1 & N/A \\
\hline
\end{tabular}

${ }^{*}$ Comorbidity scored using number of aggregated diagnosis groups. N/A Not applicable; NS Not significant

There was important variation in $\mathrm{NH}$ colonoscopy use by LHINs: $67 \%$ of $\mathrm{NH}$ colonoscopies were performed in three of the 14 LHINs. Not surprisingly, the variation in the rates of $\mathrm{NH}$-based colonoscopy among LHINs ranged widely, from one to 121 per 10,000 of the underlying population (Table 5). Overall, the rates of hospital-based colonoscopies tended to vary inversely with the rates of $\mathrm{NH}$-based colonoscopy within LHINs.

\section{DISCUSSION}

In the present study, we found that in the context of rising outpatient colonoscopy use in general, the proportion of colonoscopies that were performed in $\mathrm{NH}$ facilities increased by nearly 50\% in Ontario from 1993 to 2005. Younger, healthier men living in higher income neighbourhoods received colonoscopies in $\mathrm{NH}$ settings more frequently. Among physician attributes, high colonoscopy volumes were most strongly associated with practising in an $\mathrm{NH}$ facility; however, specialty was also important. Finally, we found significant regional variation in the use of $\mathrm{NH}$ colonoscopy.

While the selection of younger, healthier patients by endoscopists - termed 'cream-skimming' by some health 
TABLE 5

Number and proportion* of hospital- and nonhospital-based outpatient colonoscopies performed in Ontario between 1993 and 2005 according to patient Local Health Integration Network (LHIN); rates of hospital and nonhospital outpatient colonoscopies in Ontario according to LHIN for 2005

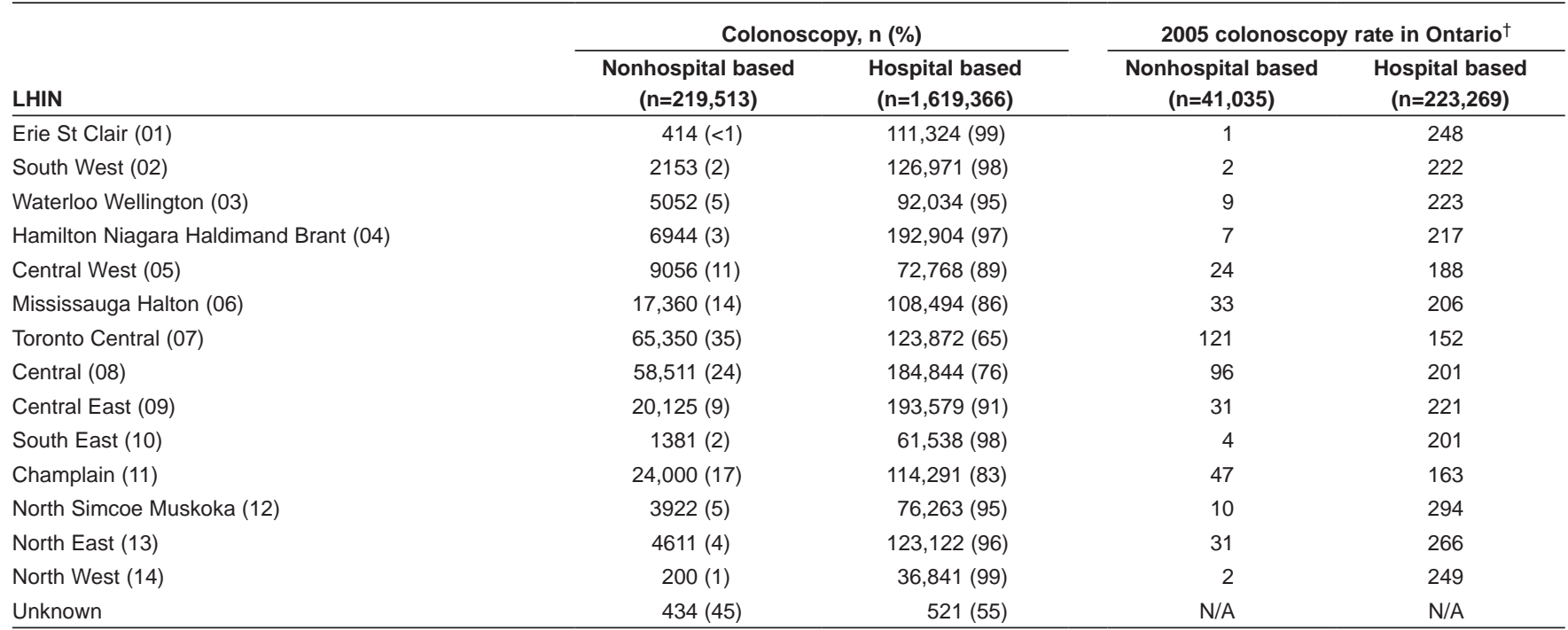

${ }^{*}$ Calculated by row; ${ }^{\dagger}$ Age- and sex-standardized rate (per 10,000 adults) using 2001 Canadian population data. N/A Not available

economists (23) - may be an intuitive explanation for the characteristics of those receiving colonoscopies in $\mathrm{NH}$ settings, we believe that this is unlikely in the Ontario context. Creamskimming is defined as the diversion of a physician's easiest cases from a public (hospital) to a private health care institution $(\mathrm{NH}$ endoscopy facility). This may occur if the physician benefits financially, often because of commercial interest in the private institution (23). However, for cream-skimming to occur, endoscopists must practice in both hospital and NH settings. During the study period, few endoscopists in Ontario practiced in both settings $(12.5 \%)$; therefore, the patient-related findings are unlikely to be explained by this phenomenon.

It is more likely that the referring physician or the patient was responsible for the observed patient selection. Primary care physicians may refer higher risk patients for colonoscopy to physicians practicing in hospitals for safety reasons because hospitals are likely better able to support patients who decompensate during a procedure. Alternatively, referring physicians may preferentially send their patients to $\mathrm{NH}$ facilities for screening rather than diagnostic colonoscopies. The latter may explain our findings because patients referred for screening colonoscopies tend to be younger and healthier than those referred for symptomrelated colonoscopies. Unfortunately, we were unable to test this hypothesis because the Ontario administrative data do not contain information regarding procedure indication. Finally, our findings may be patient driven, whereby informed, healthier patients who recognize that they are at lower risk chose private clinics possibly because of a perception that these clinics offer better access and shorter wait times than hospitals.

Physician factors were most strongly associated with receipt of $\mathrm{NH}$ colonoscopy; in particular, the association with high annual colonoscopy volume was very robust. This finding was expected because physicians in $\mathrm{NH}$ settings practice in a less restricted fashion than they do in hospitals. In fact, in most NH facilities, endoscopists may need to perform more colonoscopies to meet the financial requirements of their business plan (ie, their billings may be used to underwrite costs of operating the facility [9]). In addition, surgeons were nearly four times more likely, and other practitioners six times more likely, than gastroenterologists to perform colonoscopy in $\mathrm{NH}$ facilities. Nongastroenterologists typically receive much less formal training in endoscopy than do gastroenterologists. In a previous study, we reported that surgeons have similar rates of incomplete colonoscopies (11) or missed cancers (12) as gastroenterologists; however, low volume nonsurgeons and nongastroenterologist endoscopists had the highest rates of incomplete colonoscopy (11).

There was considerable regional variation in the use of $\mathrm{NH}$ colonoscopy, with the majority of $\mathrm{NH}$ colonoscopies performed on patients who live in three of the 14 LHINs. Interestingly, LHINs with higher rates of NH colonoscopy tended to be those with lower rates of hospital-based colonoscopy, suggesting that NH colonoscopy facilities were established because the demand for colonoscopy exceeded local hospital capacity. Alternatively, endoscopists may have chosen to perform their colonoscopies outside of hospitals despite adequate hospital capacity. Because of the limitations of administrative data, further in-depth exploration may be required at the local level to fully understand the reasons for our observations.

Variations in billing practices may lead to inaccuracies in studies using administrative data. In Ontario, endoscopy to the splenic flexure may be billed as either a flexible sigmoidoscopy (procedure code Z580) or as a colonoscopy to the splenic flexure (procedure code Z555 + E740). The latter may be billed preferentially because it is more lucrative, which may have led to the inclusion of procedures intended to be flexible sigmoidoscopies in our cohort. We reconstructed our cohort excluding all procedures billed as Z555 + E740 (data not shown). The proportions of procedures completed in hospitals and $\mathrm{NH}$ clinics were minimally changed (less than $2 \%)$; therefore, our results are unlikely to be affected by this potential inaccuracy.

We demonstrated an important increase in the proportion of colonoscopies performed in $\mathrm{NH}$ facilities. These findings are 
of interest principally in the context of previously published work (11-13) suggesting that the quality of colonoscopy in these facilities may be poorer. It should be noted that these large population-based studies reported on the quality of procedures performed before 2003. Since then, many new NH facilities have opened in Ontario and, as a result, these earlier studies may now be outdated. In fact, a single-centre study from a new $\mathrm{NH}$ clinic recently reported that they met or exceeded published benchmarks for colonoscopy (24); however, it is not possible to generalize their findings to all new $\mathrm{NH}$ clinics in Ontario. Given the increasing use of $\mathrm{NH}$ colonoscopy facilities and the changing landscape of $\mathrm{NH}$ clinics, an up-to-date population-based study of the quality of colonoscopy in both $\mathrm{NH}$ facilities and hospitals is needed.

In Ontario, hospital endoscopy units operate within institutions that are governed by the Public Hospitals Act (R.S.O. 1990 , c. P.40). This act empowers the Ontario Ministry of Health and Long-Term Care to set and enforce hospital standards of practice. By contrast, Ontario NH-based endoscopy facilities are not regulated nor are they allocated sufficient funds to cover nonphysician-related endoscopy costs. As a result, in $\mathrm{NH}$ facilities, physician credentials such as appropriate and formal training in colonoscopy, and facility standards of practice such as patient monitoring after sedation and infection control, are not scrutinized by regulatory bodies. In hospitals, the nonphysician-related endoscopy expenses (estimated at $\$ 150$ to

\section{REFERENCES}

1. Schultz S, Rabeneck L, Vinden C. Large bowel endoscopy in Ontario: Variation by geographic region and hospital type. Healthc Q 2004;7:17-8.

2. Hilsden RJ. Patterns of use of flexible sigmoidoscopy, colonoscopy and gastroscopy: A population-based study in a Canadian province. Can J Gastroenterol 2004;18:213-9.

3. Cram P, Fendrick AM, Inadomi J, Cowen ME, Carpenter D, Vijan S. The impact of a celebrity promotional campaign on the use of colon cancer screening: The Katie Couric effect. Arch Intern Med 2003;163:1601-5.

4. Ontario Ministry of Health and Long Term Care. Colon Cancer Check: Ontario's colorectal cancer screening program. $<$ http://www.health.gov.on.ca/english/public/program/colorectal cancer/colorectal_cancer_mn.html> (Accessed on June 10, 2010).

5. Government of Manitoba. Manitoba introduces colorectal cancer screening program, 2007. $<$ http://news.gov.mb.ca/news/index. html?archive $=2007-1-01 \&$ item $=1041>$ (Accessed June 10, 2010).

6. Government of Alberta. New province-wide colorectal screening program aims to save lives: New program is part of Alberta's efforts to secure a cancer-free future. $<$ http://www.gov.ab.ca/ acn/200703/212247FAFBCBO-D68C-4420-BFF8CA0FD34B7265. html> (Accessed on June 10, 2010).

7. Priest L. Lack of screening program 'very short-sighted'. The Globe and Mail, November 24, 2006.

8. Lett D. Private clinics remain unregulated in most of Canada. CMAJ 2008;178:986-7.

9. Bridges R, Adams PC. Building your Babylon. Can J Gastroenterol 2008;22:233-5.

10. University of Calgary. UCalgary and CHR open largest colon cancer screening facility in Canada. <http://wcm2.ucalgary.ca/ colonscreening/news > (Accessed on June 10, 2010).

11. Shah HA, Paszat LF, Saskin R, Stukel TA, Rabeneck L. Factors associated with incomplete colonoscopy: A population-based study. Gastroenterology 2007;132:2313-9.

12. Bressler B, Paszat LF, Chen Z, Rothwell DM, Vinden C, Rabeneck L. Rates of new or missed colorectal cancers after colonoscopy and their risk factors: A population-based analysis. Gastroenterology 2007;132:96-102.

13. Risek R, Paszat L, Stukel TA, Saskin R, Li C, Rabeneck L. Rates of complete colonic evaluation following incomplete colonoscopy and associated risk factors: A population-based study. Med Care 2009; 47:48-52.
$\$ 200$ [25]) are paid from the fixed global budgets. In contrast, a small and arguably insufficient additional OHIP fee (procedure code E749, \$22.35) may be billed for NH-based colonoscopy or flexible sigmoidoscopy to cover these expenses. As discussed above, we have previously raised concerns about the quality of colonoscopy in Ontario NH facilities (11-13). Changes to the regulation of and/or to the government funding model for these facilities could result in improvements in the quality of NH-based colonoscopy, although this has not yet been studied.

\section{SUMMARY}

The present, large, population-based study demonstrated that the proportion of colonoscopies performed in $\mathrm{NH}$ settings in Ontario is rising. We also report significant variation in the use of $\mathrm{NH}$ colonoscopy according to region and median neighborhood income. This variation and the increasing use of $\mathrm{NH}$ colonoscopy, in the context of previously published concerns regarding the quality of colonoscopy, support the need for ongoing study and an up-to-date evaluation of this practice. Furthermore, such study is critical because it may inform changes to government regulations and funding of the practice of $\mathrm{NH}$ colonoscopy in Canada.

ACKNOWLEDGEMENTS: The authors acknowledge the support of the Institute for Clinical Evaluative Sciences (Toronto, Ontario) and the Ontario Ministry of Health and Long-Term Care.

14. Johns Hopkins Bloomberg School of Public Health.

The Johns Hopkins University ACG Case-Mix System. 2007.

$<$ http://www.acg.jhsph.edu/> (Accessed on June 10, 2010).

15. Weiner JP, Starfield BH, Steinwachs DM, Mumford LM.

Development and application of a population-based oriented measure of ambulatory care case-mix. Med Care 1991;29:452-72.

16. Starfield BH, Weiner JP, Mumford LM, Steinwachs DM. Ambulatory care groups: A categorization of diagnoses for research and development. Health Serv Res 1991;26:53-74.

17. Reid RJ, Roos NP, MacWilliam L, Frohlich N, Black C. Assessing population health care need using a claims-based ACG morbidity measure: A validation analysis in the province of Manitoba. Health Serv Res 2002;37:1345-64.

18. Reid RJ, MacWilliam L, Verhulst L, et al. Performance of the ACG case-mix system in two Canadian provinces. Med Care 2001;39:86-99.

19. Deyo RA, Cherkin DC, Ciol MA. Adapting a clinical comorbidity index for use with ICD-9-CM administrative databases. J Clin Epidemiol 1992;45:613-9.

20. Singh SM, Paszat LF, Li C, He J, Vinden C, Rabeneck L. Association of socioeconomic status and receipt of colorectal cancer investigations: A population-based retrospective cohort study. CMAJ 2004;171:461-5.

21. Alter DA, Naylor CD, Austin P, Tu JV. Effects of socioeconomic status on access to invasive cardiac procedures and on mortality after acute myocardial infarction. N Engl J Med 1999;341:1359-67.

22. Government of Ontario. Local health integration networks: Building a true system. <http://www.health.gov.on.ca/ transformation/lhin/lhin_mn.html> (Accessed June 29, 2010).

23. Gonzalez P. On a policy of transferring public patients to private practice. Health Econ 2005;14:513-27.

24. Bair D, Pham J, Seaton MB, et al. The quality of screening colonoscopies in an office-based endoscopy clinic. Can J Gastroenterol 2009;23:41-7.

25. Sharara N, Adam V, Crott R, Barkun AN. The costs of colonoscopy in a Canadian hospital using a microcosting approach. Can J Gastroenterol 2008;22:565-70. 


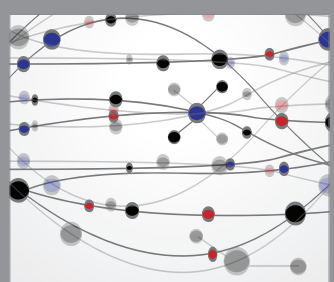

The Scientific World Journal
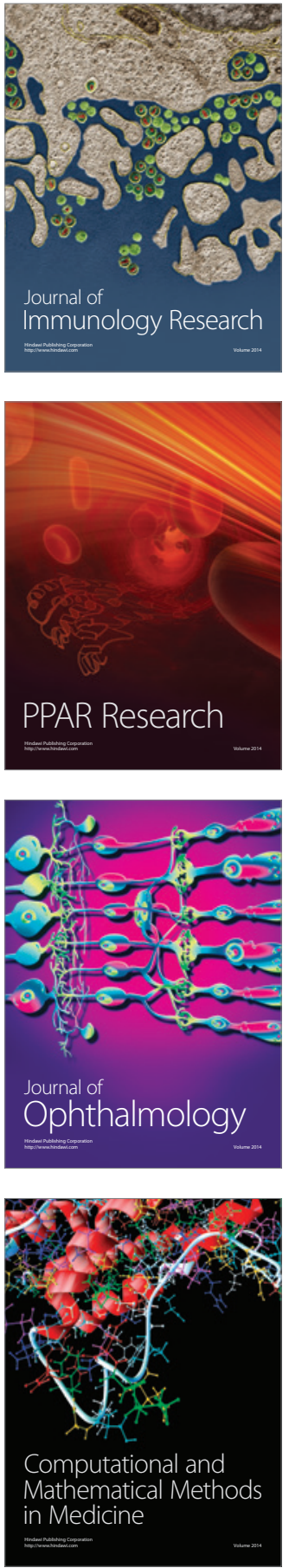

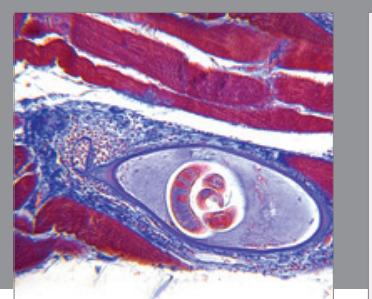

Gastroenterology Research and Practice

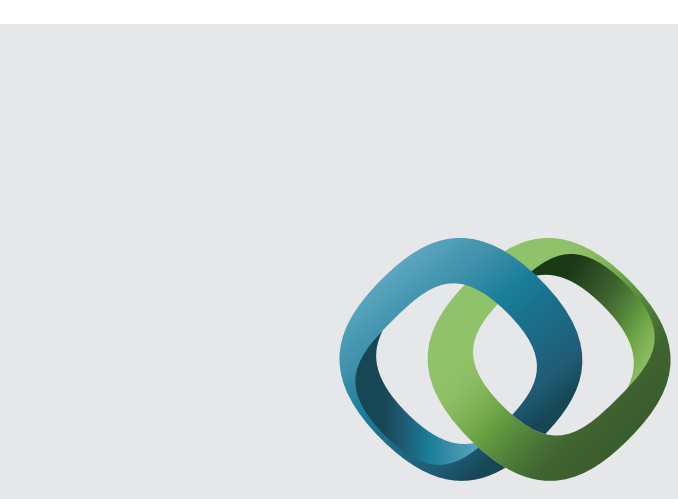

\section{Hindawi}

Submit your manuscripts at

http://www.hindawi.com
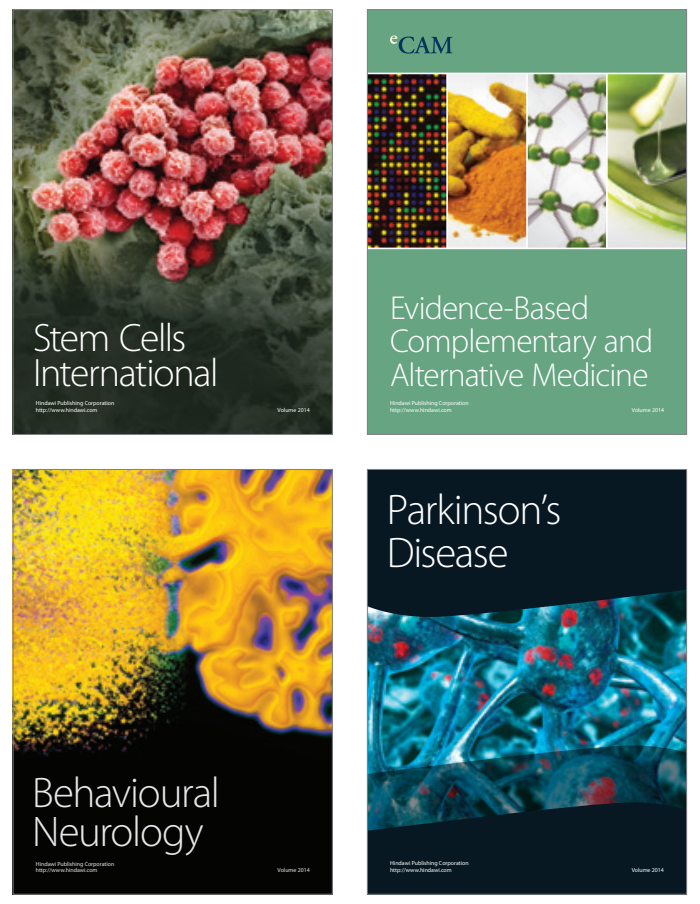
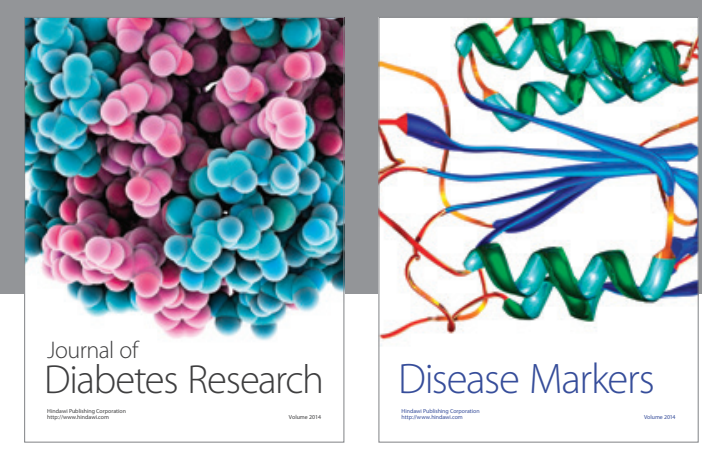

Disease Markers
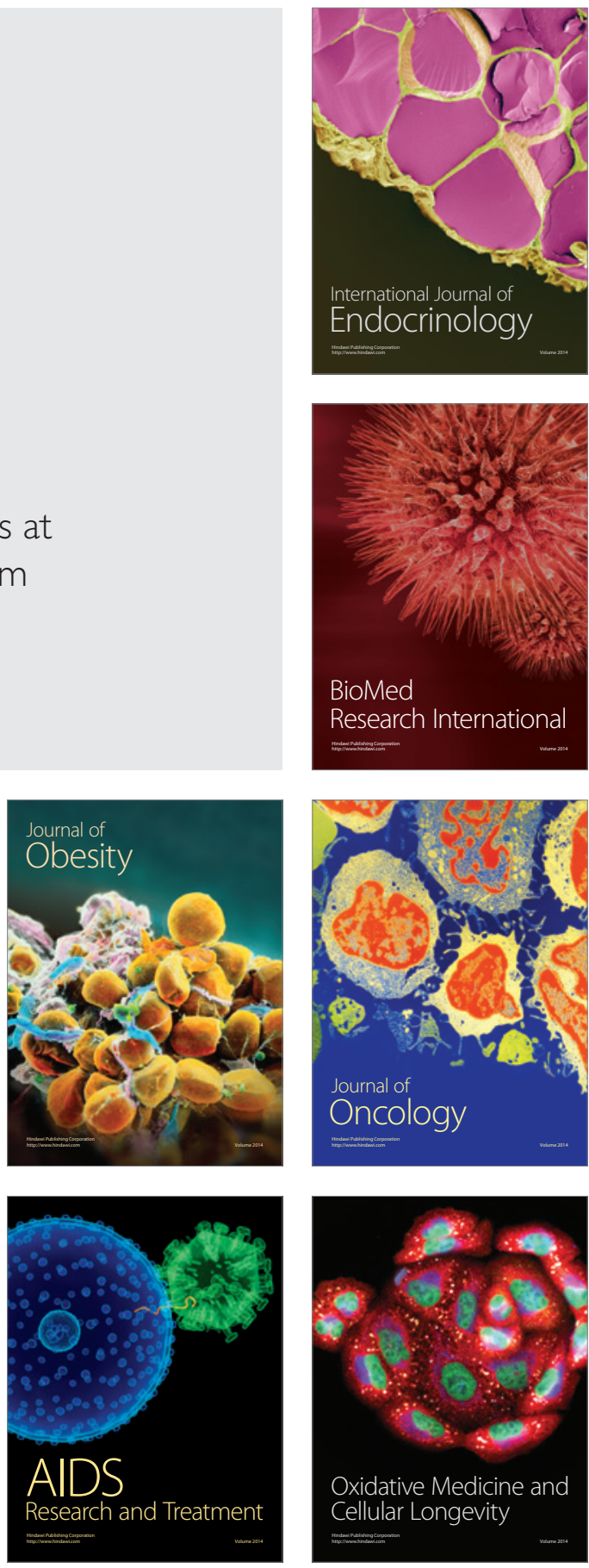